- Respiratory Protection for Ancillary Healthcare Workers (e.g., housekeepers) - a proposed 10 min module (anticipated release Fall 2017); and

- Case Study of Respiratory Protection in Healthcare - an interactive respiratory protection training for healthcare OHNs (anticipated release Fall 2017).

Conclusion AAOHN with NIOSH formed an advisory board of respiratory protection experts and developed an acclaimed national and international online respiratory protection training that meets the needs of OHNs, frontline healthcare workers, and ancillary healthcare workers. As of June 2017, over 330 individuals have completed the Respiratory Protection training.

\section{COMPARATIVE STUDY ON THE ACTIVITIES OF PART- TIME OCCUPATIONAL PHYSICIANS IN JAPAN BETWEEN 2008 AND 2016: EFFECTS OF THE STRESS-CHECK PROGRAMME}

\footnotetext{
${ }^{1,2}$ Jiro Moriguchi*, 'Masayuki Ikeda, ${ }^{1}$ Fumiko Ohashi, ${ }^{2}$ Katsuya Furuki, ${ }^{1}$ Kazuo Takeda, ${ }^{2}$ Yoichi Mori. ${ }^{1}$ Kyoto Industrial Health Association, Kyoto, Japan; ${ }^{2}$ Kyoto Medical Association, Kyoto, Japan
}

\subsection{6/oemed-2018-ICOHabstracts.305}

Introduction In 2015, implementation of the Brief Job Stress Questionnaire (also known as the 'stress-check programme') became a legal obligation for employers in Japan. The Ministry of Health, Labour, and Welfare of Japan recommends that an occupational physician (OP) should play an important role in implementing this programme. This study aimed to compare the activities of Japanese part-time OPs in 2008 and 2016 and and to investigate the effects of the stress-check programme.

Methods Questionnaires were sent via mail to 946 part-time OPs in the Kyoto prefecture of Japan in 2016. Completed questionnaires were returned by 181 OPs who were private practitioners or physicians in hospitals. Questions about the types and sizes of the industries where the OPs served, allocation of service hours, and difficulties encountered in their activities were included in the questionnaire. The responses were compared to the results of the same survey in 2008 to determine the changes in OP activities and the problems encountered after implementing the stress-check programme.

Results In 2016, 22\% of OPs utilised exceedingly long hours in the stress-check-related activities. Hours for specific health examination, health and hygiene education, health promotion activity, and development of a comfortable workplace reduced from 4.7 hours in 2008 to 2.0 hours in 2016. A total of $62 \%$ OPs frequently encountered difficulties in the stress-checkrelated activities in 2016. Many OPs also reported difficulties in the management of mental health and overwork, and support of employees' return to work in both 2008 and 2016.

Discussion Enforcement of the stress-check programme in 2015 changed the activities of part-time OPs in Japan. This programme might impose problems on OPs. Therefore, OPs should be given specific opportunities to gain more information and skills in these areas.

\section{ASSESSMENT OF PROGNOSIS BY PHYSICIANS WORKING IN THE FIELD OF DISABILITY EVALUATION: A QUALITATIVE STUDY}

${ }^{1}$ René J Kox, ${ }^{1} J a n$ L Hoving*, ${ }^{2}$ Jos H Verbeek, ${ }^{1}$ Maria JE Schouten, ${ }^{1}$ Carel TJ Hulshof, ${ }^{1}$ Haije Wind, ${ }^{1}$ Monique HW Frings-Dresen. ${ }^{1}$ Academic Medical Centre, Department: Coronel Institute of Occupational Health, Amsterdam Public Health research institute, Amsterdam, The Netherlands; ${ }^{2}$ Finnish Institute of Occupational Health, Kuopio, Finland

\subsection{6/oemed-2018-ICOHabstracts.306}

Introduction Assessment of prognosis including improvement of work functioning is challenging and research on this topic is lacking. To make this process more explicit, the following research question was formulated: Which aspects and considerations, difficulties, needs and potential solutions, affecting the prognosis assessment by physicians, working in the field of disability evaluation, can be identified?

Methods In-depth, semi-structured individual interviews were conducted with 20 physicians working in the field of disability evaluation at the Dutch Social Security Institute (UWV). Verbatim transcripts were independently analysed by two researchers until data saturation was achieved and significant themes emerged.

Results Aspects and considerations affecting the prognosis assessment consisted of medical themes including nature and severity of disease, the role of treatment, course of the disease, and medical evidence. In addition, patient-related and physician-related aspects were distinguished. Patient-related aspects as the patients' work perspectives, coping or recovery behaviour and physician-related aspects as awareness of the physicians' own role and reflection on empathy for clients and ethical considerations were deemed to be important. Difficulties described by physicians were assessment of complex diseases, applying prognostic evidence to the individual and lack of time when seeking for prognostic evidence. Needs and solutions formulated by physicians, were continuous education, better collaboration with medical specialists and/or labour experts and the use of prognostic tools like checklists, apps or internet applications to incorporate evidence on prognosis.

Discussion Physicians identified several medical and patientrelated aspects, elucidating the process of prognosis assessment. A variety of difficulties were reported and physicians expressed their needs for further support. Future research could focus on development, efficacy and feasibility of training, prognostic tools, guidelines, collaboration with labour experts or information exchange with medical doctors in different specialties.

\section{THE DEVELOPMENT OF A WORKFORCE PLANNING TOOLKIT FOR OCCUPATIONAL HEALTH NURSING SERVICES IN IRELAND}

S Carolan*, D Moriarty, S Kane, K Nolan, C Kelleher, M Cagney, N Riordan. Workplace Health and Wellbeing Unit, HSE, Human Resources, Dublin, Ireland

\subsection{6/oemed-2018-ICOHabstracts.307}

Introduction At a time when health resourcing costs are contracting, it is vital that services examine the potential to maximise the efficiency of their services and resources. 
The objective of workforce planning is to develop knowledge and intelligence data on the workforce, to inform decisions at local level and to drive improvements in Occupational Health service outcomes.

Methods Organisational Development Approach/Practice Development Approach

The workforce planning approach involved the following points -

- The main stakeholders were committed to and involved in the planning process with clear lines of responsibility and accountability being defined.

- Build from a structured information base on current staffing, and relevant activity for departments.

- The development of an overview analysis to identify need for and scope for change.

- An agreed unit workforce plan, which included a cycle of review and update.

- Support at National Level was a key factor in this project

- The Team Project was part of a Future Leaders Programme with the Royal College of Surgeons in Ireland, Institute of Leadership.

\section{Result Approved Workforce Planning Toolkit}

- The toolkit is robust addressing measurement of demand, capacity, capability, key performance indicators, and business planning.

- It has been used within the Workplace Health and Wellbeing Unit for OHS, the toolkit is continually reviewed to ensure that it is user friendly to acknowledge differences in work practices and at the same time promote standardisation.

\section{Discussion Optimising Healthcare Workers}

- This toolkit provides a framework for workforce planning within Occupational Health Nursing

- The WHO (2016) predicted a significant shortfall of healthcare workers.

- Further work needs to be done in relation to integrated succession planning for Occupational Health Services.

\section{INTERDISCIPLINARY AND EXPERIENTIAL EDUCATION IN OCCUPATIONAL SAFETY AND HEALTH}

${ }^{1}$ MA Rosen*, ${ }^{2} \mathrm{~J}$ Caravanos* ${ }^{*}{ }^{1}$ Rutgers University, Somerset, NJ, USA; ${ }^{2}$ New York University, New York, NY

\subsection{6/oemed-2018-ICOHabstracts.308}

Introduction The New York and New Jersey Education and Research Centre (ERC) provides a range of graduate continuing education for occupational safety and health (OSH) professionals in training. A key element of the education is to provide interdisciplinary and experiential education to industrial hygienists, ergonomists, occupational medicine physicians and other health and safety trainees to prepare them for the collaboration required to solve the complex occupational health and safety problems they will face in their careers.

Methods The ERC has developed an innovative interdisciplinary and experiential training approach that provides an historical aspect, while allowing the graduate students to identify solutions to occupational issues from a multi-disciplinary approach. The ERC developed a tour that brings students to sites of historical and/or contemporary significance in the occupational safety and health and environmental fields. Sites included automobile manufacturing, a coal mine, a granite quarry, fishing boats, steel manufacturing, an asbestos mine, and others.

Results The ERC has conducted twelve tours, and has included 208 trainees as participants. The participants consistently rate the tour as providing a high amount of $\mathrm{OSH}$ knowledge gained, and that the goal of providing interdisciplinary education was achieved.

Conclusion This tour has been successful in bridging the $\mathrm{OSH}$ fields to better understand how occupational and environmental exposures have occurred, in order to prevent future exposures so that workplace conditions and health can be improved. Trainees state the experiential aspect provides knowledge and skills not otherwise learned in traditional educational experiences.

\section{THE DEVELOPMENT OF STANDARDS FOR OCCUPATIONAL HEALTH SERVICES IN THE IRISH HEALTH SERVICE}

L Sisson*, J Gallagher. Workplace Health and Wellbeing Unit, HSE, Human Resources, Dublin, Ireland

10.1136/oemed-2018-ICOHabstracts.309

Introduction Standards were developed in response to concerns that Occupational Health Services were fragmented and inconsistent and that there was a requirement for standardisation nationally. Following an international trend many OHS services were seeking an accredited service that would address these concerns.

Methods One of the first priorities of the newly formed Workplace Health and Wellbeing Unit was to commence a review of existing International OHS Standards. The service developed unique standards in line with the Quality Assurance Framework (QAF) Safety and Quality Improvement Directorate. A workshop was held with HIQA to discuss the format and process to develop standards under this Framework.

A Standards Project Group was set up and included representatives from Health and Safety, Staff Health and Wellbeing and Occupational Health Services Nationwide.

In accordance with the HIQA Framework, an Expert Advisory group was also convened. 2017.

The draft standards were sent out for broad consultation, including to service users, in April 2017 and outlined to the profession at the annual WHWU conference in May 2017.

Result Standards for Occupational Health Services in the Irish Health Service were approved on May 19th 2017. ISBN 9781-78602-044-4.

The standards are grouped according to 5 themes as follows:

- Worker centred care,

- Safe and effective care

- Leadership management and governance

- Workforce planning and resources

- Use of Information

Discussion A training needs analysis was conducted and a blended approach to support the implementation of these standards will take place.

The development of standards for other divisions is under consideration. 